\title{
CA \\ Towards A Queer Futurity of Data
}

\author{
Andrea Zeffiro
}

05.17.19

Peer-Reviewed By: Tanya Clement and Amelia Acker

Clusters: Data

Article DOI: $10.22148 / 16.038$

Journal ISSN: 2371-4549

Cite: Andrea Zeffiro, "Towards A Queer Futurity of Data," Journal of Cultural Analytics. May 17, 2019.

\section{Future Visions}

On February 17th, 2017, Mark Zuckerberg published a 5,800-word Facebook post rescripting the company's Corporate Social Responsibility strategy and defining its future directions. ${ }^{1}$ The manifesto, as some commentators referred to it, declared Facebook's future vision for "developing the social infrastructure for community" and emphasized the company's focus on fostering a global community that is supportive, safe, informed, civically-engaged, and inclusive. ${ }^{2}$ "To our community," the post begins, "On our journey to connect the world, we often discuss products we're building and updates on our business. Today I want to focus on the most important question of all: are we building the world we all want?"3 Zuckerberg goes on to propose how Facebook can shape an equitable future, explaining how, "In times like these, the most important thing

\footnotetext{
${ }^{1}$ Mark Zuckerberg, "Building Global Community," Facebook, February 16, 2017, accessed November 03, 2018.

${ }^{2}$ Zuckerberg, "Building Global Community."

${ }^{3}$ Zuckerberg, "Building Global Community."
} 
we at Facebook can do is develop the social infrastructure to give people the power to build a global community that works for all of us." 4 This is a radically optimistic and persuasive agenda, and if one were to focus solely on the efforts of community building, then one might not be compelled to consider how, in fact, Facebook will achieve its future vision. Omitted from this sanguine future narrative is any mention whatsoever of data as its key asset. The basic work Facebook does is to collect data and to hold on to it for a long time, if not forever. ${ }^{5}$ Thus, the future conjured for us by Facebook necessitates the production of data by its participants, though not once is data referenced.

My contribution to this special issue of Cultural Analytics hinges on but digresses from a reflection on Zuckerberg's manifesto, and I focus instead on that which is invoked through its conspicuous absence: data. It has been nearly a year since Cambridge Analytica dominated news reports and collective fascination, and we now know more, though still not enough, as to how Facebook traffics consumer data. In this enlightened climate is knowledge truly power? Though we know more, our capacity to talk back to an entity like Facebook is limited. Short of any alternatives, some of us will choose to continue to use the platform because it is where we organize collectively and maintain ties to social groups. Others may heed to the disclosures and tighten controls over how data is shared within, across, and outside of the platform. And others yet will pull the proverbial plug and shutter their accounts. Indeed, these are choices one can make in response to Facebook's dubious data practices, but none enter into dialogue with the monolithic entity specifically, or data cultures more generally. What other options do we have to talk back?

The aim of this commentary is to move beyond critique and put forth an alternate framework to think about data cultures. Thus, this work invites a return to

\footnotetext{
${ }^{4}$ Zuckerberg, "Building Global Community."

${ }^{5}$ Brian X. Chen, "I Downloaded the Information That Facebook Has on Me. Yikes." The New York Times, April 11, 2018, accessed November 03, 2018, Keith Collins and Larry Buchanan, "How Facebook Lets Brands and Politicians Target You," The New York Times, April 11, 2018, accessed November 03, 2018, Nick Douglas, "Here's All the Data Facebook Can Learn From Your Selfies," Lifehacker, April 10, 2018, accessed November 03, 2018. Sheera Frenkel, Matthew Rosenberg, and Nicholas Confessore, "Facebook Data Collected by Quiz App Included Private Messages," The New York Times, April 10, 2018, accessed November 03, 2018, Alex Hern, "Facebook Admits Tracking Users and Nonusers Off-site," The Guardian, April 17, 2018, accessed November 03, 2018, Madison Malone Kircher, "Ever Record a Video on Facebook? Facebook Still Has It," New York Magazine, March 28, 2018, accessed November 03, 2018, John Naughton, "Data-hungry Facebook Seeks Younger Recruits," The Guardian, December 10, 2017, accessed November 03, 2018, Kurt Wagner, "This Is How Facebook Collects Data on You Even If You Don't Have an Account," Recode, April 20, 2018, accessed November 03, 2018, Chris Walters, "Facebook's New Terms Of Service: 'We Can Do Anything We Want With Your Content. Forever',' Consumerist, February 16, 2009, accessed November 03, 2018.
} 
theory, ${ }^{6}$ and not as a means to render 'big data' intelligible, but rather to draw out its limits, inadequacies, and dissonances, and to encourage new ways of thinking about the future of and with data. What follows charts the contours of 'reproductive data futurism' as a conceptual framework that seeks to reframe our thinking about data in the present in order to imagine solutions to political, social and economic problems that are otherwise framed as problems data can fix.

\section{Data as Culture as Regime of Truth}

'Big data' is a floating signifier. It is referenced in relation to our interactions and habits online, our media use and preferences, and it is named as an agent in politics, business, education, healthcare, and social services, to name but a few more prominent areas of application. Big data, then, is at once everywhere and nowhere; it is everything and nothing. It is precisely its elusiveness, which prevents us from knowing it, and in turn, sustains its authority. Working through the evasiveness of the term, I frame big data co-productively as a technical assemblage, and an ideological apparatus. Data emerge from a nexus of computational tools, techniques and protocols, and infrastructures and institutions. Data are shaped by what Alexander Galloway (2004) describes as the "protocological condition.7 "The founding principle of the Net is control, not freedom," writes Galloway. "Control has existed from the beginning." For scholars like Galloway and Wendy Chun, ${ }^{9}$ the internet is far from a 'free for all' and came into existence and continues to exist as a controlled network through which protocols, as standards, govern how technological developments are agreed to, adopted, implemented, and ultimately put into practice ${ }^{10}$ and normalizes specific behaviours, attitudes, and values that uphold and reinforce a big data paradigm. The technical assemblage and ideological apparatus create new conditions of seeing. Orit Halpern ${ }^{11}$ refers to these assumptions about the value of data as effectuating 'communicative objectivity', which are new forms of observation and rational-

\footnotetext{
${ }^{6}$ For instance, see: Chris Anderson, "The End of Theory: The Data Deluge Makes the Scientific Method Obsolete," Wired, January 26, 2008, accessed November 03, 2018.

${ }^{7}$ Alexander R. Galloway, Protocol: How Control Exists after Decentralization (Cambridge, MA: MIT, 2006).

${ }^{8}$ Galloway, Protocol, 142.

${ }^{9}$ Wendy Hui Kyong Chun, Control and Freedom: Power and Paranoia in the Age of Fiber Optics (Cambridge: MIT Press, 2006).

${ }^{10}$ Chun, Control and Freedom, 7.

${ }^{11}$ Orit Halpern, Beautiful Data: A History of Vision and Reason since 1945 (Durham: Duke University Press, 2015).
} 
ity through which we are trained and train ourselves to observe and analyze the world.

The forms of observation and rationality and the techniques and procedures that are valorized for creating new conditions of seeing are indicative of what Foucault referred to as a 'regime of truth. ${ }^{12}$ "Truth," according to Foucault, "is to be understood as a system of ordered procedures for the production, regulation, distribution, circulation and operation of statements." 13 It "is linked in a circular relation with systems of power which produce and sustain it, and to effects of power which produce and sustain it, and to effects of power which it induces and which extend it." 14 The regime of truth legitimized by "big data' is linked in a circular relation to 'dataism. ${ }^{15}$ As an ideology governing a new scientific paradigm, dataism bolsters big data to the production of truth rooted in a belief in the objective quantification of the tracking of all kinds of personal data from social media, internet platforms, and other communication technologies, as well as a trust in the institutional entities that collect, interpret, share and monetize data. ${ }^{16}$ Ten years ago, Wired editor Chris Anderson postulated how in the 'Petabyte Age', a new era marked by the influx of huge amounts of data and the statistical tools to process and analyze this data, correlation supplants causation and scientific inquiry is able to advance without the hampering of consistent models or integrated theories. ${ }^{17}$ "Who knows why people do what they do?" asks Anderson. "The point is they do it, and we can track and measure it with unprecedented fidelity. With enough data, the numbers speak for themselves." ${ }^{18}$ Indeed, Anderson's thesis is provocative by intent, written at the forefront of the mainstreaming of the term, 'big data', and yet, it persists as a master narrative that reinforces a prevailing data paradigm. A belief and trust in big data as the 'holy grail of behavioural knowledge' or as neutral 'imprints or symptoms of people's actual behaviours or moods ${ }^{19}$ validates it as a conduit towards an objective and accurate view of reality.

\footnotetext{
${ }^{12}$ Michel Foucault, Power/knowledge: Selected Interviews and Other Writings 1972-1977 (New York: Pantheon, 1980).

${ }^{13}$ Foucault, Power/knowledge, 133.

${ }^{14}$ Foucault, Power/knowledge, 133.

${ }^{15}$ Jose van Dijck, "Datafication, Dataism and Dataveillance: Big Data between Scientific Paradigm and Ideology," Surveillance \& Society 12, no. 2 (2014): 197-208, doi:10.24908/ss.v12i2.4776.

${ }^{16}$ van Dijck, "Datafication, Dataism and Dataveillance: Big Data between Scientific Paradigm and Ideology," 198.

${ }^{17}$ Chris Anderson, "The End of Theory: The Data Deluge Makes the Scientific Method Obsolete," Wired, January 26, 2008, accessed November 03, 2018.

${ }^{18}$ Anderson, "The End of Theory," 2008.

${ }^{19}$ van Dijck, "Datafication, Dataism and Dataveillance: Big Data between Scientific Paradigm and Ideology," 199.
} 


\section{Reproductive Data Futurism}

The desire to harness and wield big data is not merely an effort to comprehend the contemporary present. Predictive analytics, for instance, employ techniques and tools from data mining, modelling, statistics, machine learning and artificial intelligence to analyze current data and make predictions about the future. We are led to believe and trust that more data collected now will enable us to calibrate a clearer image of the future. 'The future' evoked here is a linearity or temporality that protracts the present (the here and the now) into the future (the there and the later). Thus, the future, in this sense, merely reproduces what already exists and persists. Building on the work of Lee Edelman, ${ }^{20}$ I propose 'reproductive data futurism' as a framework for understanding how projections about the future are intertwined with data in the present.

In No Future: Queer Theory and the Death Drive, Lee Edelman repudiates futurity and contemporary politics, arguing how both are fettered to a heteronormative logic of 'reproductive futurism', which for Edelman, entails surrendering the present for a future embedded in "the logic of a narrative wherein history unfolds as the future envisioned for a Child who must never grow up." ${ }^{21}$ The figure of the child, as Edelman describes, "has come to embody for us the telos of the social order and come to be seen as the one for whom that order is held in perpetual trust." ${ }^{22}$ The future is therefore defined by a present heteronormative social order that must be protected and safeguarded because it is the space the child will inhabit in order to uphold the reproductive logic of the present. For Edelman, reproductive futurism is a logic that underpins all aspects of society and is especially ingrained in and reproduced by contemporary politics.

Expanding on and departing from Edelman's polemic, the future in reproductive data futurism is outlined by a technosocial order that must be preserved and defended because it is the space in which data will be anchored to reaffirm the logic of the present. Data, much like the figure of the child evoked by Edelman, is a political trope through which we are coerced into the promise that more data collected now will lead to a better and brighter future. For Zuckerberg, for instance, this includes the capacity to "prevent harm" by building "social infrastructure to help our community identify problems before they happen," which demands "building artificial intelligence to understand more quickly and accurately what is happening across our community." ${ }^{23}$ Yet such a vision of the future is what

\footnotetext{
${ }^{20}$ Lee Edelman, No Future: Queer Theory and the Death Drive (Durham: Duke University Press, 2007).

${ }^{21}$ Edelman, No Future, 151.

${ }^{22}$ Edelman, No Future, 11.

${ }^{23}$ Mark Zuckerberg, "Building Global Community," Facebook, February 16, 2017, accessed
} 
Claire Birchall describes as 'structurally speculative'. "The uses to which collected data will be put and the meanings it will be given are dependent on future algorithms and political concerns." ${ }^{24}$ The examples that follow uphold reproductive data futurism in their promises of a better future. Better than what? In these future visions, technology relieves contemporary discords with a more desirable though still uncertain version of the present. Data is the precondition to fulfilling this future, and yet these examples carefully unfasten it from their narratives.

\section{Data Futures}

In December 2016 when Microsoft acquired LinkedIn for 26 billion dollars, company President and Chief Legal Officer Brad Smith nestled the deal between the Brexit vote and the American Presidential Election. In a blog post aptly titled, "Microsoft-LinkedIn deal cleared by regulators, opening new doors for people around the world," Smith wrote how,

On both sides of the Atlantic, it has become increasingly apparent that many people feel left out and unable to participate in the economic growth and opportunities created by the rising digital economy... While technology tools are not a panacea for current economic challenges, we believe they can make an important contribution... Our ambition is to do our part to create more opportunity for people who haven't shared in recent economic growth. ${ }^{25}$

Smith asks us to submit to the acquisition as an altruistic aspiration by Microsoft to create opportunities for individuals snubbed by the digital economy. Nowhere in Smith's post does he mention data from LinkedIn's 433 million members. In turn, we are more able to disregard the troves of highly personalized data now acquired by Microsoft and embrace the structurally speculative endeavour of enabling those disenfranchised to find their way into the digital economy with the help of Microsoft's steering of LinkedIn.

In the same way that Microsoft plans to use "better data and analytical capabilities to pursue economic development strategies to help connect people with

\footnotetext{
November 03, 2018.

${ }^{24}$ Clare Birchall, "Shareveillance: Subjectivity between Open and Closed Data," Big Data \& Society 3, no. 2 (2016), 6: doi:10.1177/2053951716663965.

${ }^{25}$ Brad Smith, "Microsoft-LinkedIn Deal Cleared by Regulators, Opening New Doors for People around the World," The Official Microsoft Blog, December 06, 2016, accessed November 03, 2018.
} 
new opportunities," ${ }^{26}$ Sidewalk Labs, an urban technologies company that is part of Google's parent company Alphabet, plans to build what it describes as "the world's first neighborhood built from the internet up". When the company announced its plans for a new 'smart city' on 800 acres of federally owned waterfront east of downtown Toronto, Canadian Prime Minister Justin Trudeau assured Canadians of how as a "world leader in urban innovation, Sidewalk Labs will create a testbed for new technologies... that will help us build smarter, greener, more inclusive cities which we hope to see scaled across Toronto's eastern waterfront and, eventually, in other parts of Canada and across the world." ${ }^{27}$ Quayside, as the project is called, will be equipped with sensors and cameras tracking everyone who lives, works or passes through the area. The trade-off of continuous data tracking and surveillance, as we are reassured, is that the data gathered will be used to 'instruct' the smart city to be responsive to its residents and environment. Nevertheless, in the smart city of the future, we find ourselves snagged within what Rob Kitchin has identified as a 'data paradox'. Data systems implemented to make societies more secure, safe, competitive, productive, efficient, transparent and accountable, necessarily do so through processes that in effect monitor, survey, discipline, repress, persuade, coerce and exploit individuals. ${ }^{28}$

In the examples above, reproductive data futurism is codified in part through an expectant present wherein history can be straightened out by even more data. If we invest in Microsoft's or Sidewalk Labs' reproductive data futurism, for instance, in regard to data acquisition and predictive analytics that tout to make society more equitable, then we willingly submit to their deliberately obtuse data practices. And if we are able to convince ourselves that the future these entities suggest we want is indeed the future we so desire, then we are more able to push aside any concerns we may have by virtue of our investment in reproductive data futurism.

Despite promises by Microsoft and Alphabet to produce a more desirable social order, their visions of the future, however progressive, are an endless reproduction of the same. Edelman describes politics in similar terms. "For politics, however radical the means by which specific constituencies attempt to produce a more desirable social order, remains, at its core, conservative insofar as it works to affirm a structure, to authenticate a social order, which it then intends to transmit to the future in the form of its inner Child." ${ }^{29}$ Similarly, as I argue below,

\footnotetext{
${ }^{26}$ Smith, "Microsoft-LinkedIn Deal Cleared by Regulators."

${ }^{27}$ Trudeau quoted in, Tyler Irving, "Google to Build Living Laboratory for Urban Innovation in Toronto," University of Toronto News, accessed November 03, 2018.

${ }^{28}$ Rob Kitchin, The Data Revolution: Big Data, Open Data, Data Infrastructures \& Their Consequences (Los Angeles: Sage, 2017), 165.

${ }^{29}$ Edelman, No Future, 3.
} 
Facebook affirms and authenticates what André Brock has identified as the 'social structure' of the Western Internet, which privileges and normalizes White, masculine, bourgeois, heterosexual and Christian culture. ${ }^{30}$

At face value, Zuckerberg's manifesto rescripts the company's Corporate Social Responsibility strategy in light of the company's confrontation with waves of criticism and complaints for its role in supporting the proliferation of 'fake news', a mishandling of 'Trending' topics, and its complicity in perpetuating informationfilter bubbles. We catch a glimpse of a vulnerable Zuckerberg, who admits how, "the complexity of the issues" of the last year have "been painful for me because I often agree with those criticizing us that we're making mistakes." ${ }^{31}$ Lamenting further, Zuckerberg describes how Facebook is "a work in progress" and how the company is "dedicated to learning and improving." ${ }^{32}$ If one were to concentrate on the conscience-stricken discourse and the laundry list of ways in which Facebook will foster a future through "a global infrastructure that works for everyone," then one can easily calibrate reception of the text to its apologetic undertones. Indeed, Zuckerberg's manifesto is first and foremost a public relations manoeuvre aimed at steadying what had been a tumultuous period for the company. However, embedded within the post's opaque transparency is Facebook's corporate agenda, which unwittingly leaks to us its colonial plan. Most tellingly, it does so, as Tamara Shepherd writes, "by positioning itself as an actor with a 'worldwide vantage point,' conflating its US-based culturally imperialistic perspective ('Sitting here in California') with a global 'us"' 33 And it does so too by upholding what already exists, that is, the Internet. Zuckerberg's post outlines a crucial rhetorical shift in the platform's branding. Facebook is uncoupled from 'social network', the term it became synonymous with, and in its vacancy, we encounter 'social infrastructure'. The rhetorical shift from network to infrastructure aligns neatly with Facebook's long-term goal. Facebook is no longer invested in operating as a network, rather it wants to be the network; it wants to be the internet.

\footnotetext{
${ }^{30}$ André Brock, "Beyond the Pale: The Blackbird Web Browser's Critical Reception," New Media \& Society 13, no. 7 (2011): 1085-103, doi:10.1177/1461444810397031, 1088.

${ }^{31}$ Zuckerberg, "Building Global Community."

${ }^{32}$ Zuckerberg, "Building Global Community."

${ }^{33}$ Tamara Shepherd, "Reading the Zuckerberg Manifesto," Culture Digitally, February 17, 2017, accessed November 03, 2018.
} 


\section{Data Pasts}

Prior to the publication of 'Building Global Community', Facebook's colonizing efforts were evident in Internet.org (rebranded as Free Basics in 2015), the company's philanthropic project to bring affordable mobile internet to developing regions. In August 2013, Zuckerberg shared a 10-page white paper on Facebook titled "Is Connectivity A Human Right". "For almost ten years," it begins, "Facebook has been on a mission to make the world more open and connected." ${ }^{4}$ Zuckerberg outlines how universal basic internet service is a human right and how Facebook can facilitate global connectivity. "[M]any people who have never experienced the internet" do not understand particulars about it, such as "what a data plan is or why they'd want one." 35 And yet, "most people have heard of services like Facebook and messaging and they want access to them. If we can provide people access to these services, then they'll discover other content they want and begin to use and understand the broader internet." ${ }^{36}$ However, Internet.org is not 'the broader internet'. Rather, it is akin to a walled garden that allows 'free' access only to a Facebook-sanctioned set of services. Perhaps this is why Facebook went to such great lengths to frame the project as a humanitarian effort. As Wired's Jessi Hempel recently explained, Internet.org was presented as a socially concerned effort in every respect. "Its name ended in 'dot-org,' appropriating the suffix nonprofits use to signal their do-gooder status on the web. Zuckerberg wrote that he wasn't expecting Facebook to earn a profit from 'serv[ing] the next few billion people, suggesting he was motivated by a moral imperative, not a financial one."37

Both the 2017 manifesto and 2013 white paper echo the rhetoric of the early internet, when 'visionaries' sought to secure the public's belief and trust in it with evidence of a better future. One of the most enduring myths of the history of internet is that $\mathrm{Al} \mathrm{Gore} \mathrm{created} \mathrm{it.} \mathrm{The} \mathrm{origins} \mathrm{of} \mathrm{the} \mathrm{tall} \mathrm{tale} \mathrm{are} \mathrm{in} \mathrm{a} \mathrm{March} \mathrm{9,} 1999$ interview on CNN's “Late Edition". The program's host, Wolf Blitzer, asked the sitting Vice President what distinguished him from his challenger for the Democratic presidential nomination, Senator Bill Bradley of New Jersey. Gore's response, in part, reflected on his role in promoting and fostering the economic and legislative development of the internet. As Gore explained:

During my service in the United States Congress, I took the initia-

\footnotetext{
${ }^{34}$ Mark Zuckerberg, "Is Connectivity a Human Right?" August 20, 2013, accessed November 03, 2018.

${ }^{35}$ Zuckerberg, "Is Connectivity a Human Right?" 4.

${ }^{36}$ Zuckerberg, "Is Connectivity a Human Right?"

${ }^{37}$ Jessi Hempel, "What Happened to Facebook's Grand Plan to Wire the World?" Wired, May 20, 2018, accessed November 03, 2018.
} 
tive in creating the Internet. I took the initiative in moving forward a whole range of initiatives that have proven to be important to our country's economic growth and environmental protection, improvements in our educational system. ${ }^{38}$

Gore's articulation of the stabilizing effects of technology intimates a future wherein social, political and economic problems are problems that can be alleviated by technology. Similarly, the Facebook of the future, as Zuckerberg promised in 2017, will be "for keeping us safe, for informing us, for civic engagement, and for inclusion of all." ${ }^{39}$

Perhaps one of the enduring myths to protract from contemporary digital culture is one in which Facebook, and Zuckerberg by proxy, democratize the internet. We are in the folds of such a narrative. For instance, during Facebook's Q1 2018 earnings call, Zuckerberg reported on how "our Internet.org efforts have helped almost 100 million people get access to the internet who may not have had it otherwise." 40 History unfolds as the future prescribed by and contained within the social infrastructure. Each and every individual 'helped' into Facebook's ecosystem becomes a compulsory data producer. In Althusserian terms, ${ }^{41}$ individuals are interpellated into an arrangement that is sustained by an asymmetrical relationship between those who collect, mine, store and analyze data, and those whom data collection targets. In this equation, the 'social engineers' define the problems and put forth solutions to the 'engineered'. ${ }^{2}$

\section{Compulsory Data Production}

A reliable mode of indenturing individuals into compulsory data production is to anchor specific data practices to formative social experiences. In June 2018, Facebook introduced Messenger Kids - a version of its text and video messaging app for children under the age of 13 - to the Canadian market. The app was

\footnotetext{
${ }^{38}$ Transcript: Vice President Gore on CNN's 'Late Edition', CNN, March 9, 1999, accessed November 03, 2018.

${ }^{39}$ Zuckerberg, "Building Global Community."

${ }^{40}$ Zuckerberg in, Josh Constine, "Facebook Beats in Q1 and Boosts Daily User Growth to 1.45B amidst Backlash," TechCrunch, April 25, 2018, accessed November 03, 2018.

${ }^{41}$ Louis Althusser, "Ideology and Ideological State Apparatuses," trans. Ben Brewster, in Lenin and Philosophy and Other Essays, 121-76 (New York: Monthly Review Press, 1971).

${ }^{42}$ Danah Boyd and Kate Crawford, "Critical Questions For Big Data," Information, Communication \& Society 15, no. 5 (2012): 662-79, doi:10.1080/1369118x.2012.678878; Anita Gurumurthy and Nandini Chami, "Data: The New Four-letter Word for Feminism," GenderIT.org, accessed November 03, 2018.
} 
pitched as a tool for parents to allow their children to communicate with family and close friends in an environment touted as more secure and controlled than other messaging apps. For instance, Messenger Kids is full of 'parental controls'; kids must get an adult's authorization via the adult's own Facebook account to sign up and add each new contact, it contains no ads or in-app purchases, and it does not require a child to use their real name. ${ }^{43}$ The aim to train kids to use lighter versions of social media platforms is an opportunity for them to acquire digital literacies, and there is obvious merit to such a project. Nevertheless, Messenger Kids is somewhat superfluous given how kids already communicate with close friends and family by other digital means, such as texting.

Perhaps we might also understand Facebook's app as a means of conditioning kids into data subjects. In this example, a child's early encounter with a social media platform is marked by interactions with individuals they are close to. These encounters instill a level of intimacy and familiarity in kids, but also in the adults they connect with. First and foremost, an adult's account is required to serve as an intermediary between a child and the app, and the adult is bound perfunctorily to Facebook. Beyond that, a child's enthusiasm to connect via the app may incentivize an adult to (re)engage with the social media platform and use it actively in order to communicate with and possibly monitor a child's use. In this regard, the indenture of the child to Facebook is also a reach towards the social control of adults. Indeed, the messenger are kids.

Reproductive data futurism is at play here in the way the figure of the child is fixed as a prop to secure the reproduction of a particular technosocial order underpinned by compulsory data production. By this I mean there is a natural inclination assumed by big tech that we all want to be a part of the social infrastructure. When Zuckerberg asks at the outset of his text, "are we building the world we all want?" he is not so much as asking us what world we want, but rather proposing one to us. This is a future vision accented by what some might identify as the pillars of an ideal social order: supportive, safe, informed, civically-engaged, and inclusive.

The tethering of childhood socialization to a social media platform reinforces a communicative objectivity about the value of big tech in helping shape the social practices of children. According to this logic, a child's social life is more secure and controllable - even justifying the need for 'parental control' - through an app

\footnotetext{
${ }^{43}$ Rachel Metz, "Facebook's app for kids should freak parents out." MIT Technology Review, February 7, 2018, accessed November 3, 2018; Dani. Deahl, "Facebook's controversial Messenger Kids is rolling out to Canada and Peru." The Verge, June 22, 2018, accessed November 3, 2018; Matthew Braga, "Facebook brings its messaging app for kids to Canada despite experts' concerns." CBC, June 22, 2018, accessed November 3, 2018.
} 
like Messenger Kids. And yet, this hopeful prototype of the future replicates the 'coercive universalization' Edelman identifies with the image of the Child. That is, it "serves to regulate political discourse - to prescribe what will count as political discourse - by compelling such discourse to accede in advance to the reality of a collective future whose figurative status we are never permitted to acknowledge or address." ${ }^{4}$ The desire to be a part of the social infrastructure is manufactured by anchoring compulsory data practices to the child; the literal embodiment of the future.

Some of us may rebuff an app like Messenger Kids as redundant to existing modes of communication or simply as unnecessary for kids, however, when other forms of data servitude are legitimized and normalized by disciplinary institutions, like schools, it is difficult to envision different organizing principles for communal relations to exist outside of compulsory data production. In numerous school districts in Canada and the United States, for example, Google's G Suite for Education is mandated as a teaching and learning platform. G Suite incorporates Google Classroom with other apps and services like Google Drive, Forms, Calendar, Search, Docs, Sheets, Slides and Gmail, and it boasts one online setting in which instructors can post resources and evaluation methods, communicate with students, track their progress, and share information with parents/guardians. By all measures, it is seamless and easy to use. In 2017, G Suite for Education counted more than 70 million users worldwide. ${ }^{45}$ Google's privacy policy for their education products stipulates that the company does not collect student data for advertising purposes or sell it to third parties, and the apps are also ad-free. But Google nevertheless collects data on students. ${ }^{46}$ The policy allows for the collection of information including location and GPS data, mobile network, and phone number.

The structurally speculative nature of student data is concerning because we simply do not know its life span or the ways in which it could be exploited by future algorithms and political agendas. But also, when G Suite is adopted there are few, if any, alternatives offered to students, which means they are compelled into data production. Thus, of particular concern is how instituting a corporate platform that collects, stores, and possibly shares student data with other partners, induces regulated effects of dataism.

An educational platform like G Suite conditions students, and in many instances

\footnotetext{
${ }^{44}$ Edelman, No Future, 11.

${ }^{45}$ Frederic Lardinois, "Google says its G Suite for Education now has 70M users," Tech Crunch, January 1 2017, accessed November 3, 2018.

${ }^{46}$ Jeremy Gillula and Sophia Cope, "Google changes its tune when it comes to tracking students," Electronic Frontier Foundation, October 6, 2016, accessed October 6, 2016.
} 
the adults who care for them, into ways of being/becoming in the world that are engendered, in part, through compulsory data production. It becomes easier to justify the tracking of student data because of an engrained belief and trust in educational institutions. And if we are able to accept a corporate platform as indispensable to education, then we may be less inclined to think our way out of or outside of compulsory forms of data servitude in other domains as well.

\section{Data Impasse}

Facebook, and indeed so many other corporate entities that collect and broker our data, manufacture for us scenes of fantasy of 'the good life ${ }^{\text {'47 }}$ made more possible with big data. In his "Building Global Community" statement, Mark Zuckerberg's rhetoric frames Facebook as the conduit to the objects of our desire. In the scenes of the future, we are told how data will bring happiness with close-knit communities, a safer society, economic fairness. And we need these engineered scenes of the future because, according to Zuckerberg, the problem we face is a "lack of a sense of hope for the future." He articulates this crisis in his manifesto, explaining how,

Since the 1970s, membership in some local groups has declined by as much as one-quarter, cutting across all segments of the population. The decline raises deeper questions alongside surveys showing large percentages of our population lack a sense of hope for the future... As one pastor told me: 'People feel unsettled. A lot of what was settling in the past doesn't exist anymore. ${ }^{48}$

In this example, Zuckerberg plants the roots to our collective hopelessness in the historical present, as the scene that has severed some kind of ordinary life that was supposed to continue and to which people felt optimistic and settled. ${ }^{49}$ And because we cannot go back, and we are acutely aware of this limitation and hindrance to what was, we occasionally invest in "a cluster of promises we want someone or something to make to us and make possible for us." ${ }^{50}$ We see this pervasive cultural fantasy carried beyond reproductive data futurism, in those politicized utterances about making < something $>$ great again. Zuckerberg asks

\footnotetext{
${ }^{47}$ Lauren Berlant, Cruel Optimism (Durham: Duke University Press, 2011), 14.

${ }^{48}$ Zuckerberg, "Building Global Community."

${ }^{49}$ Berlant, Cruel Optimism, 11.

${ }^{50}$ Berlant, Cruel Optimism, 23.
} 
us to believe that at some point in the future, Facebook will steer us back to where we were before, but also, somewhere better.

At play is what Lauren Berlant calls 'cruel optimism, "the condition of maintaining an attachment to a significantly problematic object." 51 Data, as the object of cruel optimism, is the thing to which we pass our fantasy of sovereignty for safe-keeping. ${ }^{52}$ For Berlant, "optimistic relation[s] are not inherently cruel" but rather, "[t]hey become cruel only when the object that draws your attachment actively impedes the aim that brought you to it initially." ${ }^{23}$ We may recognize something like Messenger Kids as a means through which we can forge new kinds of social interactions with kids, and we may identify our enthusiasm for a project like Quayside as tied to our support for sustainable cities. Our optimism toward these things, however, may not always feel optimistic. ${ }^{54}$ Any doubts we may have about the good-life fantasies these data-driven objects promise, such as questioning whether the future we are told we want is indeed the future we desire, registers an instability in our investment to these things. And yet, because our optimism for these objects is so intimately tied to what we "look forward to being in the world," 55 we preserve our "attachment to compromised conditions of possibil-

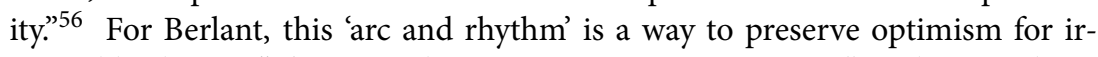
reparable objects. "The compulsion to repeat a toxic optimism" explains Berlant, "can suture someone or a world to a cramped and unimaginative space of committed replication, just in case it will be different." ${ }^{\text {"5 }}$ Similarly, reproductive data futurism persists in the way we (un)willingly consent to a future that necessitates the production of data in the present, but that remains perpetually out of reach. And because this future can never be fully realized, we reach towards it repeatedly, expecting that this time things will change in the right way. ${ }^{58}$

In the nearly two years since Zuckerberg released "Building Global Community," a lot has changed for Facebook and for its members. The company has weathered a series of crises, including foreign interference in elections, the Cambridge Analytica scandal, Zuckerberg's testimony before the U.S. Congress and European Parliament, the company's admittance to playing a role in ethnic cleansing in Myanmar, and the hiring of a PR firm to discredit critics. To put it bluntly, Facebook has failed miserably at building community. In fact, our desire for what data-driven platforms promise to be and the various ways they pledge to improve

\footnotetext{
${ }^{51}$ Berlant, Cruel Optimism, 24.

${ }^{52}$ Berlant, Cruel Optimism, 43.

${ }^{53}$ Berlant, Cruel Optimism, 1.

${ }^{54}$ Berlant, Cruel Optimism, 10.

${ }^{55}$ Berlant, Cruel Optimism, 24.

${ }^{56}$ Berlant, Cruel Optimism, 24.

${ }^{57}$ Berlant, Cruel Optimism, 259.

${ }^{58}$ Berlant, Cruel Optimism, 2.
} 
our lives are obstacles to our flourishing. ${ }^{59}$ Maybe Zuckerberg is correct in his assessment about our "lack of a sense of hope for the future." It just so happens Facebook is the object to which we direct our waning optimism. And yet, even with this awareness and with the fraying of the good-life fantasies, many of us maintain an attachment to it. It renders us impassive. This is precisely a relation of cruel optimism, ${ }^{60}$ but it is also reproductive data futurism at work.

Reproductive data futurism, much like cruel optimism, is a force that compels us to walk back from moments of unsettling revelations and from the brink of coming to terms with the reality that these data-driven entities are first and foremost revenue generating corporations. And yet, we depend on the discomfort at the realization that our optimistic attachments are flawed, for instance, in order to decipher a company's benevolent rhetoric as a smokescreen for its egregious and disorganized data practices. These instances of rupture, though short-lived, open a space for reflection, induce a creeping sense of incompleteness, and surface fleeting impulses of refusal that clarify the impotence in our hope. In this respect, we may temporarily betray the mandate of reproductive data futurism, which is rooted in "the hope of forging some more perfect social order" through data, and if we "refuse the insistence of hope itself as affirmation," we might find pockets of resistance in hope's dissolution. ${ }^{61}$

This space of fracture I describe is akin to what Berlant defines as 'the impasse',

"a stretch of time in which one moves around with a sense that the world is at once intensely present and enigmatic, such that the activity of living demands both a wandering absorptive awareness and a hypervigilance that collects material that might help to clarify things." 62

The impasse is a 'transitional moment', in which we realize that existing 'genres' can no longer make sense of the present. Berlant's conceptualization of the term helps us to rethink our impassivity in a conventional sense. We have not become insensible or immune to 'big data', nor have we lost our way. In fact, we are acutely aware of the ways in which data driven computational tools and techniques have shaped our lives. In turn, our impassivity is a "style of composure" 63 that guides us through the impasse-that 'transitional moment' of adjustment to the loss of the good-life fantasies. ${ }^{64}$ The impasse signals our capacity to conceive of alterna-

\footnotetext{
${ }^{59}$ Berlant, Cruel Optimism, 1.

${ }^{60}$ Berlant, Cruel Optimism, 1.

${ }^{61}$ Edelman, No Future, 4.

${ }^{62}$ Berlant, Cruel Optimism, 18.

${ }^{63}$ Berlant, Cruel Optimism, 5.

${ }^{64}$ Berlant, Cruel Optimism, 11.
} 
tive genres for navigating future data narratives in the present. In this sense, it is a space of contained action through which we might unlock different ways in which the interruption of norms of the reproduction of dataism can be adapted to, felt out and lived, ${ }^{65}$ and usher us towards a queer futurity of data.

\section{Queer Futurity}

The title of my piece "Towards a Queer Futurity of Data" alludes to a gesture or movement forward. First and foremost it describes the ideation presented in the text, which moves towards a reading of data cultures through the lens of reproductive data futurism. The text presents the kernels to an evolving framework that seeks to expand our perception of data cultures with particular attention to the limitations and deficiencies of contemporary data paradigms.

At the centre of this 'working through' and 'working towards' is a queer politic that begins with a rejection of 'straight time', what José Estebon Muñoz describes as "an autonaturalizing temporality" in which "the only futurity promised is that of reproductive majoritarian heterosexuality." 66 A hetero-normative logic inscribes contemporary data cultures. Indeed, it is a logic that pervades society including the technosocial. The desire to colonize global populations through data services by equating access to an enclosed technical platform as a fundamental human right is indicative of this logic. Subjugation might be packaged as a mobile internet service in the global south, a social networking site geared towards professionalization, or an educational platform that boasts a suite of tools customizable to learning needs. These examples indenture individuals into compulsory data production in the hope of realizing a future version of the contemporary present.

When reproductive data futurism entraps us in a heteronormative logic, we are less able to think through its recursiveness and reproductive power. For instance, when the figure of the child bears the burden of substantiating data as a political trope, we become invested in dataism because it is also an investment in the future child. Thus, we see here the reproduction of the heteronormative fantasy itselfthe perpetual promise of the good life fastened not only to the child but also to 'the family' as an extension of an ideal social order it reinforces. The 'normative'

\footnotetext{
${ }^{65}$ Berlant, Cruel Optimism, 199.

${ }^{66}$ José Esteban Muñoz, Cruising Utopia: The Then and There of Queer Futurity (New York, NY: New York University Press, 2009), 22.
} 
in this respect, provides an 'aspirational anchor ${ }^{267}$ for those of us whose senses of security and stability are dwindling. Thus, if constituting a new politics of truth demands a fundamental change to our "political, economic, institutional regime of the production of truth" then we need radical models to wrangle ourselves from a future manufactured by "the fraying 'good life' narratives we hold onto." 68 In this respect, we are better served to receive Zuckerbeg's question- "are we building the world we all want?" ${ }^{69}$ - not simply as a rhetorical strategy on Facebook's part, but as a genuine inquiry into the state of our attachments. Who is building this world? And for whom? We are encumbered with the task of rescripting engineered fantasies of the future with a figuration that allows people to think beyond reproductive data futurism.

Finally, the title of the piece signals also an expansion or movement outward. What I have sketched here is a partial framework for reproductive data futurism. In other words, it is incomplete. Edelman's project is an obvious and crucial starting point, yet it is limited by its intransitive insistence that the "future stops here."70 "We do not intend a new politics, a better society, a brighter tomorrow" writes Edelman, "since all these fantasies reproduce the past, through displacement, in the form of future." 71 I agree with Edelman's appraisal of how future fantasies merely reproduce the past in a future tense, but I think it is necessary to envision and experiment, by beginning to see, the alternate data futures that already exist or are currently under construction, rather than foreclose the possibility of any future. In turn, I propose we lean towards theories of queer futurity $^{72}$ to undermine data paradigms so that we can begin to see the multiplicity of nonormative logics and organizations of data that constitute, supplement, and abridge reproductive data futurism. If we can better understand the deficiencies and biases of data paradigms in the present, then we might begin to imagine possible futures and seek out strategies to support these future visions.

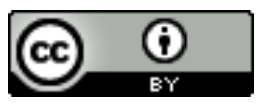

Unless otherwise specified, all work in this journal is licensed under a Creative Commons Attribution 4.0 International License.

\footnotetext{
${ }^{67}$ Lauren Berlant, "Lauren Berlant on her book Cruel Optimism," Rorotoko, June 4, 2012, accessed November 3, 2018.

${ }^{68}$ José Esteban Muñoz, "Living the Wrong Life Otherwise," Social Text, January 13, 2013, accessed November 3, 2018.

${ }^{69}$ Muñoz, "Living the Wrong Life Otherwise."

${ }^{70}$ Edelman, No Future, 30-31.

${ }^{71}$ Edelman, No Future, 3.

${ }^{72}$ Edelman, No Future; Muñoz, "Living the Wrong Life Otherwise"; Judith Halberstam. The Queer Art of Failure (Durham: Duke University Press, 2011).
} 